\title{
Reflexões sobre as possíveis contribuições da terapia ocupacional nos processos de inclusão escolar
}

\section{Considerations about the possible contributions of occupational therapy in the school inclusion process}

\author{
Eucenir Fredini Rocha ${ }^{(1)}$,Angélica Luiz ${ }^{(2)}$, Maria Aparecida Ramirez Zulian ${ }^{(3)}$
}

ROCHA, E. F.; LUIZ, A.; ZULIZN, M. A. R. Reflexões sobre as possíveis contribuições da terapia ocupacional nos processos de inclusão escolar. Rev. Ter. Ocup. Univ. São Paulo, v. 14, n. 2, p. 72-8, maio/ago. 2003.

RESUMO: O objetivo deste artigo é apresentar e problematizar as possibilidades das ações da Terapia Ocupacional no processo de inserção de crianças com deficiências na rede regular de ensino, a partir de um posicionamento epistemológico e ético diante dos conceitos que permeiam os discursos e as práticas atuais da Inclusão Escolar.

As autoras discutem, primeiramente, os conceitos de integração, de inclusão e de exclusão e suas relações com as práxis de inserção escolar e, em seguida, são apresentadas reflexões sobre as necessidades das escolas, a partir da inclusão de crianças com deficiências. Finalmente, são descritas as possíveis contribuições da Terapia Ocupacional nesse espaço, bem como a discussão de suas possibilidades.

DESCRITORES: Terapia ocupacional/tendências. Pessoas deficientes/reabilitação. Crianças portadoras de deficiência/reabilitação.

\footnotetext{
${ }^{(1)}$ Profa. Dra. do Departamento de Fisioterapia, Fonoaudiologia e Terapia Ocupacional da FMUSP. Mestre em Psicologia EscolarIPUSP e Doutora em Psicologia Social-IPUSP.

(2) Terapeuta Ocupacional pesquisadora do REATA- Laboratório de Estudos em Reabilitação e Tecnologia Assistiva do curso de Terapia Ocupacional do Departamento de Fisioterapia, Fonoaudiologia e Terapia Ocupacional da FMUSP.

(3) Terapeuta Ocupacional do Departamento de Fisioterapia, Fonoaudiologia e Terapia Ocupacional da FMUSP. Psicopedagoga. Professora do curso de Fisioterapia da Fundação Instituto de Ensino de Osasco e Professora do Curso de Pedagogia e de Psicopedagogia das Faculdades Integradas de Guarulhos. Mestre em Educação pela PUC Campinas.

Endereço para correspondência: Departamento de Fisioterapia, Fonoaudiologia e Terapia Ocupacional da Faculdade de Medicina da Universidade de São Paulo. Rua Cipotânea, 51. 05360-000. São Paulo, SP.
} 


\section{INTRODUÇÃO}

$\mathrm{O}$ objetivo deste artigo é apresentar e problematizar as possibilidades das ações de Terapia Ocupacional no processo de Inclusão Escolar de crianças com deficiências na rede regular de ensino, a partir de um posicionamento epistemológico e ético diante dos conceitos que permeiam os discursos e as práticas atuais da Inclusão Escolar.

Consideramos, para tanto, que há mensagens, de natureza explícita ou implícita, dos serviços e dos profissionais de reabilitação para as pessoas com deficiências, para os seus familiares e para a comunidade, de que a meta final do trabalho reabilitacional é a inclusão social. A inclusão escolar é hoje considerada o primeiro passo nessa direção. Assim, entendemos como fundamental a discussão das contribuições específicas da Terapia Ocupacional nesse processo.

\section{Integração x inclusão}

O conceito de integração, fortemente influenciado pelos serviços especializados de reabilitação da década de 50 em diante (ROCHA, 1999, p. 14), remete-nos a uma compreensão da inserção social da pessoa com deficiência a partir do seu esforço pessoal e individual. O paradigma de partida é a organização de serviços especializados cujo foco de ação ocorre sobre a pessoa com deficiência, visando o desenvolvimento de suas habilidades e competências para a sua adaptação ao meio social. Ou seja, a ação tem por finalidade o indivíduo, com o intuito de minimizar as consequiências de suas incapacidades, a partir de serviços especializados, e, consequientemente, desencadear a inserção da pessoa com deficiência no meio social.

Da década de 80 para cá, há um movimento internacional, que congrega pessoas com deficiências, profissionais e a sociedade civil de uma forma geral, que propõe o redirecionamento dessa finalidade, introduzindo o conceito de inclusão social (SASSAKI, 1997).

Nessa abordagem, o paradigma de base propõe uma sociedade de suportes, ou seja, uma sociedade responsável por todos os seus membros, com mecanismos que proporcionem o acolhimento de forma indiscriminada, com possibilidades efetivas de participação. Assim, para a inserção das pessoas com deficiência, faz-se necessário o ajuste da comunidade, dos espaços, das leis, enfim, de toda a coletividade, nessa direção. Há, portanto, nesse paradigma, a preconização imperativa do ajuste social na direção da inclusão de todos, o foco deixa de ser o indivíduo e passa a ser o coletivo.
Ao abandonarmos o conceito de integração social estamos abdicando do conceito de que a pessoa com deficiência "deve ser", prioritariamente, preparada para a sua inserção social e de que o papel do terapeuta ocupacional está voltado para a introdução de estratégias que minimizem as suas incapacidades. Negamos a proposição de normalização do comportamento e do corpo do indivíduo, bem como a sua culpabilização pela situação de marginalização e segregação social.

Com o paradigma da inclusão social vislumbrase uma organização na qual todos são responsáveis por todos, assim, a participação das pessoas com deficiência depende da organização de redes sociais de suporte. Parte-se da premissa de que a sociedade inclusiva é a melhor e de que a conscientização; o estabelecimento de leis, assim como o seu cumprimento; e a educação popular são os pilares que embasam as estratégias para a efetivação da proposta.

Dessa forma, o caminho da concretização da sociedade inclusiva passa por ações de normatização não mais da pessoa com deficiência, mas da coletividade, na qual todos devem estar adaptados ao convívio com as diferenças, preparados para elas, aceitando-as como possibilidade de existência.

No entanto, a proposta de inclusão, tal como afirmada por diferentes autores, está despojada de uma discussão problematizadora, ou seja, não considera os aspectos que produzem a exclusão e a intolerância em suas manifestações afetivas e de sofrimento, no cotidiano e no presente, das pessoas com diferenças físicas, mentais, sociais, raciais etc.

Dessa forma, a nossa perspectiva em relação ao tema em pauta é da rejeição por completo do conceito de "Integração Social" e da problematização do conceito de "Inclusão" (ROCHA, 2001, 2002), considerando, para tanto, a sua relação dialética com a Exclusão, enquanto conceito e fenômeno social.

\section{Inclusão x exclusão}

Optamos pela expressão "dialética exclusão/ inclusão" como coloca Sawaia (1999):

A sociedade exclui para incluir e esta transmutação é condição da ordem social desigual, o que implica o caráter ilusório da inclusão. Todos estamos inseridos de algum modo, nem sempre decente e digno, no circuito reprodutivo das atividades econômicas, sendo a grande maioria da humanidade inserida através da insuficiência e das privações, que se desdobram para fora do econômico (p.8).

Nessa perspectiva, não é possível discutir somente a partir dos aspectos "macro" dos problemas 
relacionados à exclusão/inclusão, como as leis, as políticas públicas, as organizações sociais, entre outros. Torna-se necessário introduzir a ética e a subjetividade nas análises. Deparamo-nos, assim, com as histórias dos indivíduos ou dos grupos sociais que vivem, no cotidiano e no presente, situações de sofrimento, abandono, discriminação, injustiças, enfim, diversas modalidades e configurações da exclusão como "descompromisso político com o sofrimento do outro" (SAWAIA, 1999, p.8).

Entendemos, assim, que a criança com deficiência que está excluída da rede regular de ensino pode estar incluída em outra lógica. Pode estar na instituição especializada (escola, centro de reabilitação, instituições de abrigo), ou estar inserida no circuito de todos aqueles que vivem a segregação familiar, internadas em suas próprias casas, sem possibilidade de acesso ao mundo externo. Ou seja, nesse universo, torna-se parte de uma lógica perversa da inclusão, é objeto, muitas vezes, de ações assistencialistas, paternalistas, de piedade, de inserção nas políticas públicas de assistência social para grupos sociais “desfavorecidos". Torna-se, portanto, parte do universo social do que é considerado indesejável para os cidadãos comuns e ao mesmo tempo objeto de piedade, estigma e preconceito.

Essa lógica, inclusive, pode permear a sua inserção nas escolas da rede regular de ensino, ou seja, esta criança pode estar no espaço educativo comum como uma concessão, sendo considerada objeto de dó e não sujeito participante dos processos educacionais. Entendemos, portanto, que não é suficiente a criança com deficiência estar matriculada e frequientando a escola regular de ensino, pois apenas isto não garante seu processo de aprendizagem e socialização. Sem os apoios necessários, ela pode estar alijada dos processos educacionais comuns à totalidade dos alunos e a escola poderá se configurar, assim, como um espaço de exclusão ou de inclusão perversa.

Para Sawaia (1999, p. 107), a exclusão deve ser entendida como um processo complexo, com diferentes qualidades, com diferentes expressões (individual/coletiva, subjetiva/objetiva, racional/ emocional, relacional/pessoal), que não é uma falha do sistema que deve ser combatida e sim como um produto do seu funcionamento. Enfim, um fenômeno multifacetado com diferentes configurações e expressões, nos indivíduos ou nos grupos, com aspectos emocionais e afetivos envolvidos, bem como com diferentes possibilidades de sofrimento em relação ao tema.

Assim, ao falar-se de exclusão, "fala-se também de desejo, temporalidade e de afetividade, ao mesmo tempo que de poder, de economia e de direitos sociais"
(SAWAIA, 1999, p. 98).

E, do nosso ponto de vista, fala-se também da necessidade de revermos as possíveis formas de intervenção nesse universo, criando novos modos, novos desenhos de ações, capazes de superar as propostas de conscientização e de convencimento, que visam comportamentos "corretos" em relação às pessoas com deficiências.

Consideramos os mecanismos de exclusão como manifestações providas de emoções, como o medo diante do desconhecido, de preconceitos e de outras dificuldades vividas pelas diferentes pessoas, com deficiências ou não, no cotidiano e no presente, que ao serem explicitados podem sugerir mecanismos de superação das limitações diante do novo e do difícil. Ou seja, o desvelamento dos diferentes sentidos que a deficiência adquire para os envolvidos e a desconstrução de um imaginário supersticioso em relação à deficiência e às diferenças podem ser uma chave para superarmos os processos de exclusão social e escolar. necessidades...

Inclusão escolar: o processo atual, as

Com a nova Lei de Diretrizes Básicas para a Educação, a inserção de crianças com deficiências está garantida por lei no Brasil. Em muitos municípios essa proposta vem se efetivando na última década. Em paralelo à legislação, muitas famílias de crianças com deficiência também têm solicitado das escolas, de forma crescente, a inserção escolar.

Zulian (2002, p.86) coloca que existe, no momento atual, um hiato entre a proposta de inclusão das crianças com deficiência na rede regular de ensino e a formação dos professores. Quando o professor tem alguma formação voltada para a educação da criança com deficiência, essa capacitação está no âmbito da educação especial, ou seja, ele é especializado em Deficiência Mental, Visual, Auditiva, entre outras, e não considera as diferentes possibilidades e dificuldades, independentemente da patologia. O professor preparado para a inclusão deveria ser o professor capacitado para diferentes estratégias pedagógicas, possíveis de serem aplicadas com diferentes alunos, independentemente de a criança ser deficiente ou não.

Além das questões relativas à capacitação do educador, deve-se lembrar que a maioria dos espaços escolares conta hoje com muitas barreiras arquitetônicas, falta de mobiliários adaptados, ausência de equipamentos de ajuda e de materiais pedagógicos adequados para as diferentes dificuldades (visuais, auditivas, cognitivas e motoras). Esses fatores, apesar 
de não serem determinantes, também dificultam o acesso pleno ao espaço regular de ensino.

Paralelamente à preparação dos professores, dos equipamentos, dos materiais pedagógicos e dos espaços físicos, há o fato de que a maioria das crianças com deficiência não conta com serviços de saúde e de reabilitação. Muitos alunos não têm tratamentos básicos que facilitariam o seu desenvolvimento e, portanto, o seu processo de aprendizagem formal.

Nesse contexto, os professores se sentem órfãos em uma proposta que necessita de parcerias e apoios, desconhecem questões básicas sobre as condições dos alunos com deficiência e muitas vezes se sentem impotentes em sua ação específica. A ignorância sobre aspectos peculiares às deficiências $\mathrm{e}$ sobre as possibilidades de cada criança também gera situações de medo, de recusa, de preconceito em relação à presença do aluno deficiente em sala de aula. Temos, assim, alunos impotentes, desmotivados e professores assustados e reativos, acreditando que o aluno deficiente é um grande problema, aliado aos outros já recorrentes na escola. Como consequiência há uma despotencialização do professor como educador e da criança como aprendiz. Muitas vezes, vivem-se situações de faz-deconta que a criança está na escola. Ela somente assiste o que ocorre ao seu redor e o professor não se responsabiliza pelo ensino e avaliação desse aluno. Muitos alunos com deficiência "passam" pela escola por um período de suas vidas, depois a abandonam, sem nenhum projeto de vida acadêmica futura.

Parte dessa responsabilidade é dos serviços de saúde que não proporcionam nenhum tipo de suporte para as famílias, para as crianças e para os educadores. Por outro lado, quando se propõem a fazê-lo persistem numa perspectiva clínica organicista, voltada a aspectos exclusivamente individuais e referentes à patologia. Essa modalidade de participação também contribui para a construção do imaginário de que as questões da deficiência são do campo das especialidades, mesmo na educação. É como se o aluno, o professor e a escola, como um todo, necessitassem de "tratamento" para "aceitar" a criança com deficiência.

Ao mesmo tempo, não se conta, também, em nossa realidade, com outros serviços, como transporte, projetos culturais e sociais que poderiam apoiar o processo educativo inclusivo.

Configura-se nesse cenário diversas situações de inclusão de caráter perverso ou de exclusão do processo educacional desejável a todos. Persiste o imaginário social segundo o qual a pessoa com deficiência é um problema, coitada, doente, objeto de dó e de caridade, entre outros estigmas e preconceitos tão comuns. Portanto, o processo de inclusão está preso, como coloca Espinosa (CHAUÍ, 1995, p. 91), às paixões tristes, que despotencializam os homens.

\section{O terapeuta ocupacional no espaço escolar}

A partir de um compromisso ético-político com o sofrimento do outro, entendemos que as contribuições da Terapia Ocupacional no campo da inserção escolar devem se dar na direção de uma práxis inspirada na busca das paixões alegres, como coloca Espinosa:

... onde a alegria ocupa papel crítico seletivo, indicando que os homens devem ser determinados a agir por um afeto de alegria, mas não qualquer alegria, só as positivas, sendo a principal delas a de pensar sem submissão e afastar tudo o que nos causa medo e tristeza e gera superstição (SAWAIA, 1999, p.116).

A partir dessa perspectiva entendemos que a ação da Terapia Ocupacional na escola não é clínica, nem voltada a aspectos específicos dos alunos com deficiência, tampouco de convencimento de atitudes corretas e, muito menos direcionada a rever questões pedagógicas.

Trata-se sim, de um trabalho a ser desenvolvido com os educadores, os alunos, os pais, a comunidade, cuja finalidade é a facilitação do aparecimento das dificuldades, dos sentimentos, das emoções que permeiam o relacionamento com a proposta da inclusão, desvelando os sentidos que a deficiência tem para todos e debatendo os aspectos que permeiam o imaginário social do grupo. No entanto, desvelar não é um ato de conscientização, mas uma ação de decomposição das paixões tristes e da composição de paixões alegres por meio de bons encontros, boas composições, nas quais professores, crianças com deficiência, família, comunidade e sociedade são objetos e sujeitos dessa nova produção, em direção à redefinição de um novo sentido para a deficiência e inclusão social.

Esse processo, que podemos denominar como um diálogo, pode se dar de diferentes formas. Muitas vezes, é através da ação, das atividades.

As diferentes possibilidades de intervenção da Terapia Ocupacional, tais como o uso de tecnologia assistiva, as possibilidades de ações na dinâmica de grupos, assim como a análise de atividades, a facilitação das atividades da vida diária e da vida prática, a introdução da comunicação alternativa, entre outras, são estratégias possíveis para esse diálogo.

O rompimento dos medos e a superação das 
dificuldades relacionais e de dificuldades de atividades no cotidiano podem se dar através de ações específicas como, por exemplo, a introdução da comunicação alternativa para o aluno com Paralisia Cerebral que, na escola, era considerado sem nenhuma possibilidade de aprendizagem, só assistia às aulas sem nenhum retorno para o professor e para o grupo de alunos. Com o instrumento de comunicação, novas relações são possíveis, há a manifestação de seu potencial e há a possibilidade do fortalecimento das capacidades do professor como educador.

Entendemos, assim, que a Terapia Ocupacional pode utilizar-se de suas diferentes formas de ação, não como um fim em si mesmas, mas como um meio capaz de colaborar na explicitação das dificuldades que todos podem ter em relação a como lidar com as diferenças, propondo, de forma objetiva, no cotidiano e no presente, o desmonte dos empecilhos aparentes da inclusão escolar. Ao eliminar as dificuldades explícitas, como barreiras arquitetônicas, ausência de tecnologia assistiva, por exemplo, tornase necessário o enfrentamento das dificuldades implícitas no processo de inserção. Esse enfrentamento pode dar-se através de atividades no coletivo e no individual e a Terapia Ocupacional pode apoiar os educadores e os alunos, visando constituir bons encontros, capazes de fortalecer a todos nas atividades desenvolvidas.

Portanto, a meta da Terapia Ocupacional, no espaço escolar, é o fortalecimento da potência de ação dos educadores e dos educandos, facilitando a emergência de soluções para os impasses a partir do próprio grupo, utilizando-se de diferentes atividades, adequadas às necessidades de cada realidade.

\section{Possíveis estratégias da terapia ocupacional no espaço escolar}

Crianças com comprometimentos motores, com deficiência mental, distúrbios de atenção, dificuldades no campo comportamental e/ou emocional ou com déficits sensoriais podem possuir diferentes demandas, porém, é necessário criar soluções ao mesmo tempo particulares e coletivas, pois estar na escola pressupõe estar em grupo, em diferentes espaços e em diferentes atividades. Assim, ao pensarmos nas ações da Terapia Ocupacional no espaço escolar, propomos intervenções que primem por uma abordagem baseada em princípios universais, ou seja, as adequações ambientais, dos equipamentos e mobiliários. Os temas debatidos devem atender a diferentes possibilidades de inclusão, pois alunos com diferentes deficiências podem freqüentar a mesma escola.

Ações objetivas no espaço escolar são necessárias e possíveis, tais como a eliminação das barreiras arquitetônicas; o acesso fácil aos equipamentos, ao mobiliário e ao material pedagógico/escolar adaptado; a capacitação dos educadores em relação aos tipos de dificuldades geradas pelas diferentes deficiências e a introdução de novas formas de participação, em diferentes atividades.

A Terapia Ocupacional pode contribuir para a constituição de ambientes acessíveis e confortáveis, primeiramente, avaliando as barreiras arquitetônicas presentes nos diferentes ambientes da escola e propondo soluções a partir das normas da Associação Brasileira de Normas Técnicas. A introdução de rampas, elevadores, apoios de barras, parques e pátios acessíveis, brinquedos adaptados e/ou inclusivos, assim como a indicação da iluminação adequada, a introdução de diferentes sinalizações e sistemas de alertas (tátil, visual, auditiva), do melhor posicionamento das crianças no mobiliário e dos móveis no espaço de forma a facilitar a participação de todos, são ações necessárias e que devem considerar a premissa de que todos os ambientes devem ser acessíveis e confortáveis.

Outra frente de trabalho pode ser a facilitação do acesso do aluno com deficiência aos recursos de informática, adequando os programas e adaptando os equipamentos para as necessidades das crianças com deficiências físicas, auditivas, visuais e cognitivas (softwares especiais, ponteiras, adaptações em teclados e mouses etc.).

A introdução da tecnologia assistiva adequada às necessidades advindas de diferentes incapacidades, tais como engrossadores de lápis, giz de cera, suporte de livros, cadernos, lupas etc, bem como a capacitação dos educadores para sua indicação e uso adequado pelos alunos, também pode ter um caráter esclarecedor dos limites e alcances desse tipo de aparato tecnológico na relação do aluno com o meio e com a aprendizagem. Além disso, o apoio da Terapia Ocupacional pode proporcionar reflexões a respeito da autonomia do professor, ajudando-o a observar as necessidades de cada criança e a criar junto com ela as soluções para suas dificuldades.

Considerando as necessidades particulares de cada aluno com deficiência é importante o esclarecimento de aspectos específicos relacionados às suas dificuldades e a explicitação do potencial de cada criança, desmistificando possíveis entendimentos errôneos, tais como supor incapacidades que não são 
próprias de cada quadro de deficiência ou inferir limites a partir de estereótipos relacionados a algumas deficiências. Essas informações podem proporcionar subsídios para os professores durante o planejamento das atividades pedagógicas.

Cabe ainda ressaltar a introdução da comunicação suplementar ou alternativa para as crianças com dificuldades nesse campo. Esse trabalho pressupõe uma participação ativa do professor para a sua implementação.

Outra contribuição pode ser a indicação de possíveis trabalhos terapêuticos e o encaminhamento aos serviços de saúde e de reabilitação necessários para tanto. Nesse contexto, cabe lembrar também a necessidade de orientar e encaminhar os familiares para os serviços que fornecem equipamentos de auxilio, órteses, próteses e cadeiras de rodas, muitas vezes, necessários para que as crianças adquiram maior independência e conforto nas suas atividades escolares. Esse encaminhamento pode ser para locais privados ou para postos credenciados específicos do Sistema Único de Saúde.

Para discutir os temas relativos à inclusão, são possíveis diferentes dinâmicas grupais, oficinas de atividades, filmes, leituras de textos com alunos, educadores e comunidade. Tais atividadesfacilitam as reflexões e os diálogos sobre as configurações dos temas propostos na realidade do grupo.

\section{A potência da ação em contraposição à potência de padecer}

As ações supostamente objetivas, como as acima explicitadas, são apenas meios para o estabelecimento de possíveis diálogos em torno da questão dos sentidos que a deficiência e a inclusão pode ter para todos na escola. Através delas, os medos, as dificuldades, os preconceitos e as idéias supersticiosas podem ser reveladas e desmontados, e no vazio da desconfiguração original dessas emoções vinculadas às paixões tristes há a possibilidade de constituírem-se novos sentidos, significados, na direção da composição de paixões alegres. Entendemos, assim, que nenhuma ação é apenas objetiva, desvinculada de emoções, afetos. E é através desses sentimentos que outras possibilidades relacionais se constituem.

Do ponto de vista afetivo e intersubjetivo se faz necessário ações que proporcionem "bons encontros" entre os envolvidos, com profundidade emocional e continuidade no tempo. Esses bons encontros devem ser pautados por uma ação no presente, pois é nele que se configuram os afetos e as emoções, em relação ao que é a deficiência, ao convívio, ao ensino e à aprendizagem de crianças com deficiência. No cotidiano é que pequenas soluções contribuirão para a resignificação da inclusão escolar e da deficiência e para a potencialização dos atores envolvidos no processo de ensino e aprendizagem.

Os bons encontros, nesse sentido, devem direcionar a relação do sujeito com o outro no processo de inserção escolar. $\mathrm{O}$ fortalecimento da necessidade desses encontros, propiciando a realização individual a partir e com o grupo, é, ao mesmo tempo, o fundamento e a meta do trabalho da Terapia Ocupacional no processo de inserção escolar.

ROCHA, E. F.; LUIZ, A.; ZULIZN, M. A. Considerations about the possible contributions of occupational therapy in the school inclusion process. Rev. Ter. Ocup. Univ. São Paulo, v. 14, n. 2, p. 72-8, maio/ago. 2003.

\begin{abstract}
The pourpose of this article is to present and to argue about the possibilities of the Occupational Therapy actions inside the inserction process of handicapped children in regular school, starting from an epistemological and ethical position about the concepts that interpose the real speaches and practices of school inclusion. First of all, the authors argue about integration, inclusion and exclusion concepts, and their relationship with the praxis of school inserction, and then, they present some reflections about the schools necessities in front of inclusion of handicapped children. Finaly, they describe the possible Occupational Therapy contributions in this field of knowledge, as well as the argument of those possibilities.
\end{abstract}

KEY WORDS: Occupational therapy/trends. Disabled persons/rehabilitation. Disabled children/ rehabilitation. 
ROCHA, E. F. et al. Reflexões sobre as possíveis contribuições da terapia ocupacional nos processos de inclusão escolar.

\section{REFERÊNCIAS}

CHAUÍ, M. Espinosa: uma filosofia da liberdade. São Paulo: Editora Moderna, 1995. 112p.

ROCHA, E. F. Do corpo orgânico ao corpo relacional: uma proposta de deslocamento dos fundamentos e práticas de reabilitação da deficiência. 1999. 237f. Tese (doutorado) - Instituto de Psicologia, Universidade de São Paulo. São Paulo, 1999.

SASSAKI, R. K. Inclusão: construindo uma sociedade para todos. Rio de Janeiro: Editora EWA, 1997.

Recebido para publicação: Janeiro de 2003

Aceito para publicação: Março de 2003
SAWAIA, B. As artimanhas da exclusão: análise psicossocial e ética da desigualdade social. Petrópolis: Vozes.1999. 156p.

ZULIAN, M. A. R. Formação de professores da escola regular para receber a criança portadora de necessidades motoras especiais. 2002. 95p. Dissertação (Mestrado) Campinas, Faculdade de Educação da Pontifícia Universidade Católica de Campinas, 2002. 